\title{
Low-carbohydrate dieting: what's going
} on?

\author{
Jarl S. Torgerson \\ Obesity Outpatient Unit, Sahlgrenska University Hospital, Göteborg, Sweden
}

\section{Abstract}

Low-carbohydrate diets have become increasingly popular in recent years. A review of available clinical trials indicates that there is not enough information on efficacy and safety to make clear recommendations for or against the use of such diets in obesity treatment. Unfortunately, too many published studies have methodological shortcomings, making interpretation of data difficult.

Keywords: Clinical trials; low-carbohydrate diet; obesity; risk factors; treatment

The increase in the global prevalence of obesity is rapid. About $10 \%$ of the adult Scandinavian population have a body mass index (BMI) $>30 \mathrm{~kg} \mathrm{~m}^{-2}$ and in the market economies an average of $20 \%$ are obese. Treatment and prevention of obesity is thus of utmost importance to the medical community and to society as a whole. This is reflected by the recent WHO report, "Obesity: preventing and managing the global epidemic" (1). Similarly, the Swedish Council on Technology Assessment in Health Care has published an evidence-based review of obesity treatment, "Fetma - problem och åtgärder" (2).

There is a large amount of public interest in obesity, often focusing on new and spectacular treatment options. Data from the USA indicate that during the late 1990s one-third of the population tried to lose weight, while another third restricted food intake to remain weight stable. Consequently, there is a huge market for dieting and weight loss products.

One treatment strategy that has become increasingly popular during recent years is low-carbohydrate diets. In the mass media this has often been seen as a royal road to weight loss. Against this background it is important that Bravata et al. recently published a systematic review of lowcarbohydrate diets focusing on both weight loss and effects on cardiovascular risk factors (3).

A MEDLINE search gave 2600 potentially interesting articles. However, only 94 studies fulfilled given inclusion criteria (adults, more than 4 days of treatment, outpatient, relevant information on out- come). Only 43 of these studies were randomized. The selected studies were separated by carbohydrate intake (below/above $60 \mathrm{~g}^{\mathrm{day}^{-1}}{ }^{\text {). Diets with a }}$ carbohydrate intake $\leq 60 \mathrm{~g} \mathrm{day}^{-1}$ had a significantly higher fat content $(104 \pm 65$ vs $69 \pm 58 \mathrm{~g}$ day $^{-1}, p=0.01$ ), while the total energy intake was significantly lower $(1446 \pm 653$ vs $1913 \pm 880 \mathrm{kcal}$ day $\left.^{-1}, p=0.002\right)$. The average treatment time tended to be shorter in studies with $\leq 60 \mathrm{~g} \mathrm{day}^{-1}$ $(50 \pm 70$ days $)$ than in studies with $>60 \mathrm{~g} \mathrm{day}^{-1}$ (73 \pm 83 days) $(p=0.10)$. There was no difference between groups with respect to gender distribution, age, BMI, or levels of lipid, glucose, insulin or blood pressure.

Bravata's main finding was that there was no significant difference in weight loss between the two low-carbohydrate diet groups when studies with the best design (randomized controlled trials and randomized cross-over trials) were analysed. The below-60 group lost $3.6 \pm 1.2 \mathrm{~kg}$ [95\% confidence interval $(95 \% \mathrm{CI}) 1.2-6.0 \mathrm{~kg}]$ and the above-60 group lost $2.1 \pm 0.3 \mathrm{~kg}(95 \%$ CI $1.6-2.7 \mathrm{~kg})$.

A further analysis of the 22 diets with the greatest mean weight loss ( $\geq 10 \mathrm{~kg}$ ) showed that they varied widely in carbohydrate content (mean 97, range 10-271 $\mathrm{g} \mathrm{day}^{-1}$ ). They had a lower total energy intake $\left(1077,525-1800 \mathrm{~g} \mathrm{day}^{-1}\right)$ and a longer duration (142, 42-365 days) and included heavier patients $(101,84-183 \mathrm{~kg})$. Longer treatment time $(p=0.008)$, higher baseline body weight $(p<0.001)$ and lower total energy intake $(p=0.03)$ were associated with final weight loss, while carbohydrate content was not. Accordingly, Bravata et al. 
concluded that baseline weight, energy intake and treatment duration might be more important for final weight loss than the actual carbohydrate content.

In the below-60 group there were no significant effects on cholesterol [total, high-density lipoprotein (HDL), low-density lipoprotein (LDL)] or triglyceride levels. In the above-60 group there was a significant, although small, reduction in total cholesterol levels $\left(-0.21 \pm 0.04 \mathrm{mmol} 1^{-1}, 95 \%\right.$ CI -0.14 to $-0.28 \mathrm{mmol}^{-1}$ ), while other serum lipid levels were unaffected. There were no significant effects on glucose, insulin or blood pressure levels in any of the groups. Again, restriction of carbohydrate content was not associated with any outcome variable, whereas treatment duration, baseline weight and total energy restriction contributed significantly to the reduction in LDL cholesterol.

Since Bravata's review some further low-carbohydrate studies have been published. Samaha et al. randomized 132 obese patients (BMI $43 \mathrm{~kg} \mathrm{~m}^{-2}$ ) to either a low-carbohydrate diet $\left(\leq 30 \mathrm{~g} \mathrm{day}^{-1}\right)$ or a low-fat diet $\left(-500 \mathrm{kcal} \mathrm{day}^{-1}, \leq 30 E^{\%}\right.$ fat $)$ for 6 months (4). Thirty-nine per cent of the patients had diabetes and $43 \%$ had the metabolic syndrome. Subjects in the low-carbohydrate group lost $5.8 \pm$ $8.6 \mathrm{~kg}$ after 6 months compared with $1.9 \pm 4.2 \mathrm{~kg}$ in the low-fat group $(p=0.002)$. The low-carbohydrate group had a significantly greater reduction in triglyceride levels and the insulin sensitivity (only non-diabetics examined) was also significantly improved. The amount of weight loss and lowcarbohydrate diet treatment both contributed significantly to these improvements in risk factors.

Foster et al. randomized 63 obese subjects to either a low-carbohydrate diet (Atkin's diet) or a more conventional hypocaloric diet for 12 months (5). There was no difference in final weight loss between the low-carbohydrate group $(-4.4 \pm 6.7 \%)$ and the conventional diet group $(-2.5 \pm 6.3 \%)$ $(p=0.26)$. However, after 3 and 6 months the lowcarbohydrate group had lost significantly more weight. Both HDL and triglyceride levels were significantly more improved in the low-carbohydrate than in the conventional diet group, whereas no long-term differences were seen in total or LDL cholesterol.

Based on their systematic review, Bravata et al. conclude that there is not enough evidence about efficacy and safety to make clear recommendations for or against low-carbohydrate diets (3). The publication of Samaha's and Foster's studies does not appear to change this conclusion $(4,5)$. The popularity and commercial success of lowcarbohydrate diets thus do not rely solely on evidence-based medicine, which is important to keep in mind, especially since a vast majority of the available studies have far too short treatment periods ( $<3$ months). With Samaha's study as a quite rare exception there is also very little information on low-carbohydrate diets in obese patients with metabolic and cardiovascular complications.

Too many short-term clinical obesity trials have been published over the years. Initial exploratory trials must of course always be performed, but since obesity is a chronic disease more long-term interventions are definitely needed. There is no real clinical challenge in producing short-term ( $<6$ months) weight loss. Almost any strategy will help as long as it results in negative energy balance. The important goal is long-term maintenance of weight loss and above all the reduction in morbidity and mortality that might come out of this (6). As shown by Bravata's review, not only length of treatment but also the lack of randomized clinical trials are problematic and make interpretation of the data even more difficult. Furthermore, a high dropout rate is a notorious problem in obesity trials (7). This can be dealt with statistically in different ways (8), but it also highlights the tolerability of different diets. Palatability and satiety might be important factors in achieving long-term dietary adherence and are thus important areas for future research.

\section{References}

1. WHO. Obesity: Preventing and managing the global epidemic. Technical Report Series 894. Geneva: World Health Organization; 2000.

2. SBU. Fetma - problem och åtgärder. En systematisk litteraturöversikt. Stockholm: The Swedish Council on Technology Assessment in Health Care; 2002.

3. Bravata DM, Sanders L, Huang J, Krumholz HM, Olkin I, Gardner CD, et al. Efficacy and safety of lowcarbohydrate diets. A systematic review. JAMA 2003; 289: $1837-50$.

4. Samaha FF, Iqbal N, Seshadri P, Chicano KL, Daily DA, McGrory J, et al. A low-carbohydrate as compared with a low-fat diet in severe obesity. N Engl J Med 2003; 348: 2074-81. 
5. Foster GD, Wyatt HR, Hill JO, McGuckin BG, Brill C, Mohammed BS, et al. A randomised trial of a lowcarbohydrate diet for obesity. N Engl J Med 2003; 348: 2082-90.

6. Torgerson JS, Sjöström L. The Swedish Obese Subjects (SOS) study - rationale and results. Int J Obes 2001; 25(Suppl 1): S2-4.

7. Glenny AM, O'Meara S, Melville A, Sheldon TA, Wilson C. The treatment and prevention of obesity: a systematic review of the literature. Int J Obes 1997; 21: 715-37.
8. Ware JH. Interpreting incomplete data in studies of diet and weight loss. N Engl J Med 2003; 348: 2136-7.

JS Torgerson

Department of Body Composition and Metabolism, Vita Stråket 15, Sahlgrenska University Hospital, SE-4I 345 Göteborg, Sweden Tel: 46 3। 3424046

E-mail: jarl.torgerson@medfak.gu.se 